\title{
The Effect of Increasing Surface Area of Dialyzer Membrane on Adequacy of Hemodialysis
}

\author{
Faiza Saeed, Ashar Alam, Shoukat Memon, Salman Imtiaz
}

\section{ABSTRACT}

Introduction: The patients with end stage renal disease requires 12 hours of hemodialysis per week divided in three equal sessions ( 4 hours/day for 3 days/week). Some studies show that adequacy of hemodialysis can be maintained by increasing the surface area of the dialyzer membrane and decreasing the frequency of treatment which can help the poor socioeconomic status patients in getting effective hemodialysis at a low cost.

Objectives: To observe whether by increasing the surface area of dialyzer the dose of dialysis can be reduced against the standard hemodialysis prescription.

\section{Study design: Randomized Control Trial.}

Study Duration: Six months from March 2017 to August 2017.

Settings: Department of Nephrology, The Indus Hospital Karachi.

Subjects: ESRD patients undergoing Hemodialysis for at least 6 months at The Indus Hospital Karachi.

Methods: In this prospective randomized control study, a total of 60 patients of end stage renal disease receiving hemodialysis for more than six months were included and divided into 2 groups randomly (Arm-A: twice weekly dialysis using a larger surface area dialyzer and Arm-:B thrice weekly dialysis using regular surface area dialyzer).

Results: A total of 59 (30 in Arm A and 29 in Arm B) patients were enrolled in the study out of which majority of the patients were male (59.3\%). On average significantly higher $U R R$ and $\mathrm{eKt} / \mathrm{V}$ were reported in Arm A whereas, higher mean standard (weekly) stdKt/V was reported in Arm-B.

Conclusion: Standard protocols should be followed to maintain the adequacy of Hemodialysis.

Keywords: Dialyzer, hemodialysis, hemodialysis adequacy.

Published Online: November 30, 2021

ISSN: $2736-5476$

DOI: $10.24018 /$ ejclinicmed.2021.2.6.130

F. Saeed*

Nephrology Department, The Indus Hospital, Karachi, Pakistan.

(e-mail: faiza.saeed@tih.org.pk)

A. Alam

Nephrology Department, The Indus Hospital, Karachi, Pakistan.

(e-mail: ashar.alam@tih.org.pk)

S. Memon

Nephrology Department, The Indus Hospital, Karachi, Pakistan.

(e-mail: shoukat.memon@tih.org.pk)

S. Imtiaz

Nephrology Department, The Indus Hospital, Karachi, Pakistan.

(e-mail: salman.imtiaz@tih.org.pk)

\section{INTRODUCTION}

There is a ceaseless rise in the number of patients all over the world, who are dependent on different forms of renal replacement therapies which include hemodialysis, peritoneal dialysis or kidney transplantation. Dialysis is a resourceintensive therapy, therefore, people living in developing countries are speculated to suffer the consequences due to economic deprivation and cost of the treatment. There is huge variability in prevalence of CKD in different parts of the world, due to various environmental, ethnic, socio economical and urban rural differences and the impact of this rising trend is more pronounced in the developing countries [1], [2]. This impact not only induces a socio-economical degradation of the country, but also on an individual patient either on hemodialysis or in a pre-dialysis stage [3].

The lives of thousands of patients with end stage renal failure (ESRD) have been protracted with the availability of Hemodialysis (HD). The purpose of the HD system is to deliver blood in a fail-safe manner from the patient to the dialyzer, enable the efficient removal of uremic toxins and excess fluid, and deliver the cleared blood back to the patient. The main components of the dialysis system are the extracorporeal blood circuit, the dialyzer, the dialysis machine, and the water purification system [4]. Traditionally hemodialysis is recommended thrice weekly, each session lasting for four hours. The National Kidney Foundation Hemodialysis Outcome Quality Initiative (NKF-DOQI) guides the current measures of hemodialysis adequacy as treatment related urea reduction ratio (URR) and fractional 
urea clearance $(\mathrm{Kt} / \mathrm{V})$ [5]. There is also a concept of standard $\mathrm{Kt} / \mathrm{V}(\operatorname{stdKt} / \mathrm{V})$, which is an average of all session done in aweek, calculated by Leypoldt equation [6] and this stdKt/V is recommended to be above 2.0.

The primary treatment variables that determine the actual dose of hemodialysis are blood flow rate, dialysate flow rate, composition of dialysate fluid, duration of treatment and composition and surface area of dialyzer membrane. The dose of hemodialysis can be increased by increasing the surface area of the dialyzer membrane as large dialyzer (surface area $2.2 \mathrm{~m}^{2}$ ) has a higher ability to remove urea [5]. Therefore, the delivered dose of hemodialysis can be improved by selecting dialyzer with a larger surface area as suggested by [7], [10]. Reference [9] found that increasing the surface area of the dialyzer membrane from $1.15 \mathrm{~m}^{2} \pm 0.1$ to $1.7 \mathrm{~m}^{2}$, the $\mathrm{Kt} / \mathrm{V}$ was increased from $0.93 \pm 0.19$ to $1.55 \pm 2.9(\mathrm{p}<0.05)$ and URR were increased from $52 \pm 8 \%$ to $71 \pm 7 \%(\mathrm{p}<0.05)$, that is there was $66.7 \%$ and $36 \%$ increment in $\mathrm{Kt} / \mathrm{V}$ and URR respectively.

Since we are living in a developing country where the situation of CKD is gruesome, shown in a recent review of CKD status in this region [10]. We conducted this study to find out that by increasing the dialyzer surface area with reduction in number of hemodialysis sessions per week can maintain required weekly dialysis dose to help the poor socioeconomic people.

\section{OBJECTIVE}

To compare the mean urea clearance and stdKt/V in patients undergoing twice weekly dialysis using a larger surface area dialyzer (Group A) to those in patients undergoing thrice weekly dialysis using regular surface area dialyzer (Group B).

\section{MATERIAL AND METHODS}

This Randomized Control Trial was conducted at Department of Nephrology, The Indus Hospital Karachi, a free of cost tertiary care facility. All the patients who gave informed consent, of age between 18 and 75 years, getting thrice weekly hemodialysis via AVF for at least 6 months, with body surface area $1.5-2.0 \mathrm{~m}^{2}$ sured by Dubois \& Dubois formula, their dialyzer was $1.8 \mathrm{~m}^{2}$, and who had good enough AVF to tolerate a blood flow of $250 \mathrm{ml} / \mathrm{min}$ were included in the study over a period of 6 months from March 2017 to August 2017. While patients with active ongoing infection suggested by fever and/or rising total leukocyte count $\left(>11 \times 10^{9} / \mathrm{L}\right)$ and lacking a permanent angio access were excluded from the study.

All the eligible patients were divided into two groups randomly using SNOSE protocol [11], Group A: twice weekly dialysis using a larger surface area dialyzer. Group B: thrice weekly dialysis using regular surface area dialyzer.

Blood sample was drawn for calculation of serum urea prior to and after hemodialysis. In both groups, dialysate flow rate was $500 \mathrm{ml} / \mathrm{min}$ and blood flow rate around $250 \mathrm{ml} / \mathrm{min}$. Blood sampling was done aseptically before hemodialysis from the A-V access through arterial needle and subsequently after completion of hemodialysis from another hand to avoid the risk of post hemodialysis urea rebound and access recirculation. A brand-new dialyzer (FRESENIUS F7/F8) was used for all the patients. Serum urea level was measured by Berthelot method while URR and standard Kt/V were calculated using the standard formula.

\section{Statistical ANALYSis}

Data was entered and analyzed using SPSS version 21.0. Mean \pm standard deviation was computed for continuous variables such as age, pre\& post dialysis weight, height, pre\& post dialysis urea, urea clearance and stdKt/V. Frequency and percentage was computed for categorical variables like gender. Independent sample t-test was applied to check significant differences in urea clearance and stdKt/V between the two groups and t-test was also applied to assess significant difference in mean urea clearance and stdKt/V for both the groups controlling for age and gender. Univariate and multivariable linear regression analysis was performed to assess significant risk factors associated with stdKt/V, URR, and $\mathrm{eKt} / \mathrm{V}$. All the variables with $\mathrm{p}$-value $<0.25$ or of clinical significance were included in the final multivariable analysis. $\mathrm{P}$-value $<0.05$ was considered significant.

\section{RESUlts}

A total of 60 patients were included in the study with equal sample size in both the groups. One patient from Arm-B (thrice weekly dialysis + regular surface area dialyzer) was excluded from the study due to incomplete information. Out of 59 patient's majority were males $(n=35,59.3 \%)$ with equal distribution of gender in Arm-A (twice weekly dialysis+ larger surface area dialyzer) however, in Arm-B majority of the participants were males ( $\mathrm{p}=0.041$, Table I). No significant difference was found in age, height, pre-dialysis weight, predialysis body surface area (BSA), and pre-dialysis blood flow rate between both the groups (Table I). However, pre-dialysis urea was found to be significantly higher in Arm A in comparison to Arm B (Table I). In addition, URR, and eKt/V was found to be significantly higher in Arm-A in comparison to Arm-B whereas, stdKt/V was found to be higher in Arm B as compared to Arm A (Table I).

\section{A. Risk Factors associated with stdKt/V}

Furthermore, in univariate analysis age, and study arms were found to be significant factors effecting standard (weekly) Kt/V. Results revealed that with one unit increase in age the stdKt/V will increase by 0.005 unit ( $\mathrm{p}=0.01$, Table II). In addition, patients who received twice-weekly dialysis with larger surface area dialyzer (Arm A) were found to have 0.54 times lower stdKt/V in comparison to the patients who received standard treatment of care $(p=0.000$, Table I).

Multivariable analysis showed that patients in Arm-A had 0.59 times lower stdKt/ $\mathrm{V}$ in comparison to Arm-B adjusting for age and gender $(p=0.000$, Table II). Moreover, results showed that females had 0.2 times lower stdKt/V as compared to males adjusting for other variables $(p=0.010$, Table II). 


\section{B. Risk Factors Associated with URR}

Age, female gender, and study arms were found to be significant risk factors associate with URR in univariate analysis. However, in multivariable analysis post-dialysis BMI and body surface area were also found to be significant risk factor associated with URR. Results showed that URR was 7 times higher in Arm-A in comparison to Arm-B adjusting for other variables (Table III).

\section{Risk Factors associated with eKt/V}

On univariate analysis, only study arms were found to be significantly associated with eKt/V. However, in multivariable analysis age and body surface area were also found to be significant risk factor associated with URR. Results showed that $\mathrm{eKt} / \mathrm{V}$ was 0.32 times higher in Arm-A in comparison to Arm-B adjusting for other variables (Table IV).

TABLE I: CHARACTERISTICS OF THE STUDY PARTICIPANTS ACCORDING TO THE STUDY ARMS

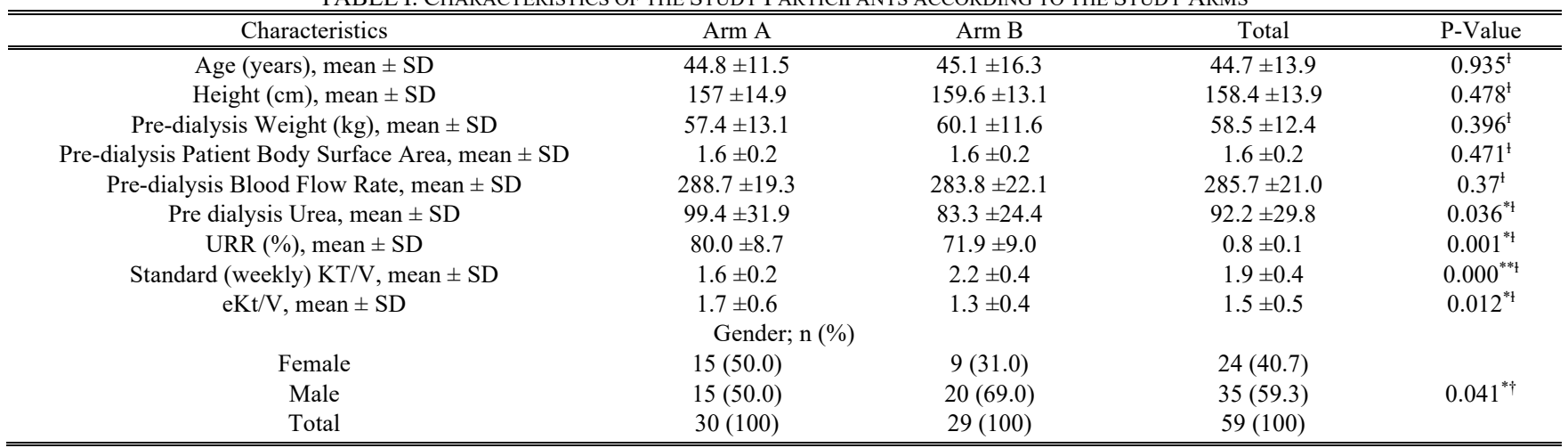

$*$ P-value $<0.05, * * \mathrm{P}$-value $<0.0001$, f Independent Sample T-Test, $\dagger$ Chi-square test.

TABLE II: FACTORS EFFECTING STANDARD (WEEKLY) KT/V

\begin{tabular}{|c|c|c|c|c|}
\hline \multirow{2}{*}{ Variables } & \multicolumn{2}{|c|}{ Univariate analysis } & \multicolumn{2}{|c|}{ Multivariable analysis } \\
\hline & Coefficient $(95 \% \mathrm{CI})$ & P-value & Adjusted Coefficient $(95 \% \mathrm{CI})$ & P-value \\
\hline Constant & - & - & $2.26(1.9,2.6)$ & $0.000^{* *}$ \\
\hline Age & $0.005(-0.003,0.012)$ & $0.01^{*}$ & $0.005(0.000,0.10)$ & $0.048^{*}$ \\
\hline Post-dialysis BMI & $0.01(-0.01,0.03)$ & 0.293 & - & - \\
\hline Patient Body Surface Area & $-0.06(-0.6,0.5)$ & 0.835 & - & - \\
\hline \multicolumn{5}{|c|}{ Gender } \\
\hline Female & $0.045(-0.17,0.26)$ & 0.673 & $-0.2(-0.34,-0.05)$ & $0.010^{*}$ \\
\hline Male & \multicolumn{2}{|c|}{ ref } & \multicolumn{2}{|l|}{ ref } \\
\hline
\end{tabular}

TABLE III: FACTORS EFFECTING URR

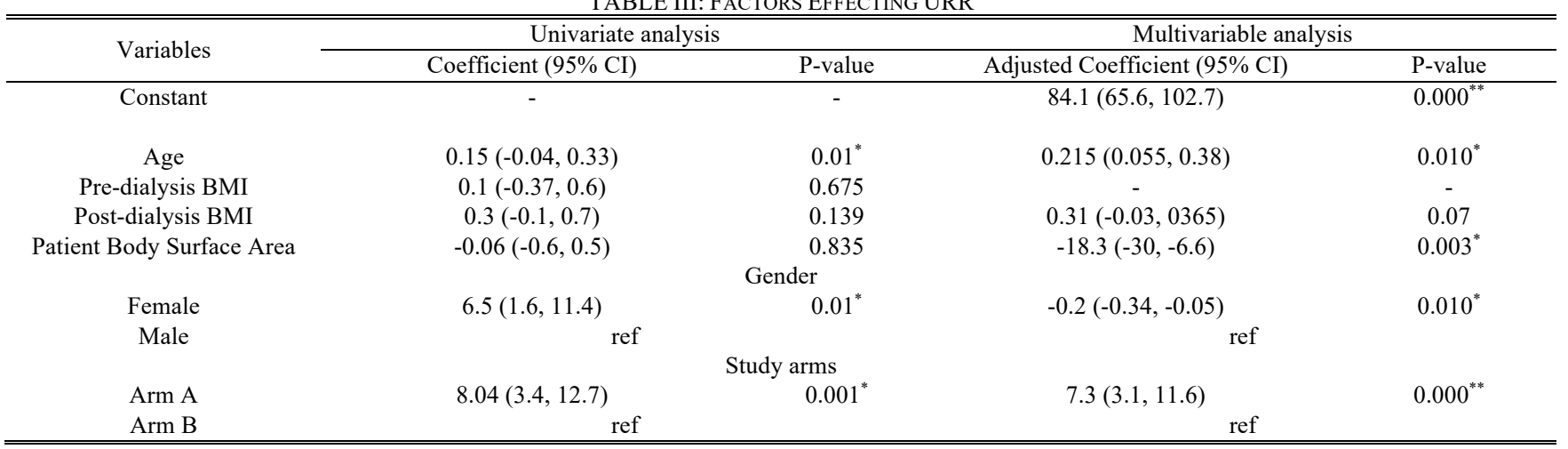

TABLE IV: FACTORS EFFECTING EKT/V

\begin{tabular}{|c|c|c|c|c|}
\hline \multirow{2}{*}{ Variables } & \multicolumn{2}{|c|}{ Univariate analysis } & \multicolumn{2}{|c|}{ Multivariable analysis } \\
\hline & Coefficient $(95 \% \mathrm{CI})$ & P-value & Adjusted Coefficient (95\% CI) & P-value \\
\hline Constant & - & - & $2.11(1.02,3.2)$ & $0.000^{* *}$ \\
\hline Age & $0.008(-0.002,0.02)$ & 0.135 & $0.012(0.002,0.021)$ & $0.022^{*}$ \\
\hline Pre-dialysis BMI & $0.001(-0.02,0.03)$ & 0.917 & - & - \\
\hline $\begin{array}{c}\text { Post-dialysis } \\
\text { BMI }\end{array}$ & $0.005(-0.02,0.03)$ & 0.686 & - & - \\
\hline $\begin{array}{l}\text { Patient Body } \\
\text { Surface Area }\end{array}$ & $-0.64(-0.14,0.08)$ & 0.079 & $-0.82(-1.5,-0.11)$ & $0.024^{*}$ \\
\hline $\begin{array}{l}\text { Female } \\
\text { Male }\end{array}$ & $\begin{array}{r}0.26(-0.02,0.55) \\
\text { ref }\end{array}$ & $\begin{array}{l}\text { Gender } \\
0.660\end{array}$ & ref & - \\
\hline Arm A & $0.35(0.0,0.62)$ & $\begin{array}{c}\text { Study arms } \\
0.012^{*}\end{array}$ & $0.322(0.06,0.58)$ & $0.000^{* *}$ \\
\hline Arm B & ref & & ref & \\
\hline
\end{tabular}




\section{DISCUSSION}

To our best knowledge this is the first randomize control study conducted in Pakistan +to see the effect of increasing the dialyzer surface area on adequacy of hemodialysis. This study reveals that by increasing the dialyzer surface area and reducing the frequency of hemodialysis from three session per to two session per week reduces the efficacy of dialysis procedure.

There are few factors which need to elaborate before embarking on the result. Diffusion is the main process by which removal of small solute is chiefly obtained. An additional mechanism is Convection which is typically essential for larger molecules [12]-[14]. We do not use convection in our hemodialysis procedure, the addition of convection in the ongoing conventional hemodialysis may increase the clearance which needs to explore in our population in a prospective control study. Therefore, the competence of a high flux hemodialyzer is (even we are using) dependent on its ability to expedite the diffusion process [15]-[17]. The factors that affect diffusion include blood and dialysate flow rates, surface area of the dialyzer, temperature and thickness of the membrane. The adequacy of hemodialysis can be measured in a single session by URR or single pool $\mathrm{Kt} / \mathrm{V}$ however stdKt/V has to be calculated to estimate its adequacy over a week. Keeping in mind the different factors contributing to the adequacy, Ahmed Tahir Athar concluded in his study that significantly improved $\mathrm{Kt} / \mathrm{V}$ and URR has been observed in moderate and high efficiency dialyzers by increasing dialysate flow rate to $800 \mathrm{~mL} / \mathrm{min}$ from usual $500 \mathrm{~mL} / \mathrm{min}$ [18].

In late seventies the idea to motivate shorter dialysis time with high urea clearance rates led to the development of highefficiency hemodialysis. Later in the 1990s, high flux dialysis was recognized with the evolution of certain biocompatible features and the desire to remove amyloidogenic $\beta 2$ microglobulin. Thereafter, the use of conventional membranes declined with increasing usage of high-efficiency and high flux membranes. In 1994, a survey done by the Centers for Disease Control showed that in United Stated $45 \%$ of dialysis centers used high-flux dialysis while $51 \%$ of these used high-efficiency dialysis [19].

Therefore, superiority of high flux membranes was suggested by several controlled studies with respect to the uremic syndrome, such as Beta2 amyloidosis [20], loss of residual renal function [21], dyslipidemia [22], polyneuropathy [23] and infection, although other studies remained inconclusive [24]-[26].

In Pakistan, each hemodialysis session costs about 40006000 Rupees to a patient, and with the medications and investigation, this cost goes even higher. Moreover, the cost of transportation to dialysis facility further increases the burden. Therefore, in our country due to poor socioeconomic condition, the ESRD patients prefer two days per week hemodialysis and develop various complications due to inadequate removal of uremic toxins. To overcome this problem, current study was conducted to see if the adequacy of dialysis is increased in single session (URR) by increasing the surface area of the dialyzer membrane and simultaneously reducing the frequency of hemodialysis to two per week and then measuring the impact on weekly hemodialysis dose adequacy (standard Kt/V). Although sufficient literature is available on measuring hemodialysis adequacy and the factors responsible for it but very few has compared the effect of dialyzer surface area on the adequacy of hemodialysis. Reference [8] had done a similar study in Bangladesh, however their study was restricted to measuring adequacy in single dialysis session by URR and single pool (Kt/V) while increasing surface area of dialyzers and they did not couple this to decreasing frequency of hemodialysis per week. Their results came significant ( $p$ value $<0.001)$ and they concluded that single session adequacy can be increased by increasing the surface area of dialyzers. Our study is unique in the way that we, in addition to measuring the impact of dialyzer surface area, also measured the effect of reducing weekly frequency of hemodialysis in same patients on overall weekly hemodialysis dose. We got the same result with respect to single session adequacy (URR) that was significantly better ( $p$ value $<0.001$ ) in patients subjected to larger surface area dialyzers. However, at the same time, as these patients were dialyzed only twice a week, the adequacy of weekly hemodialysis dose $(\operatorname{stdKt} / \mathrm{V})$ turned out to be significantly lower than the control group with patients being dialyzed thrice weekly with normal surface area dialyzer ( $p$ value 0.000 ). This weekly adequacy was even lower than the recommended value of 2.0 set by NKF-DOQI. Therefore, we conclude that although increasing the dialyzer surface area can increase the dialysis adequacy in a single session but if the frequency of hemodialysis is reduced, the weekly dialysis dose becomes inadequate and should not be recommended.

\section{Conclusion}

Although increasing the dialyzer surface area can increase the dialysis adequacy in a single session but if the frequency of hemodialysis is reduced, the weekly dialysis dose becomes inadequate and should not be recommended. Further studies are required to observe the clinical wellbeing of the patient being given the inadequate weekly hemodialysis dose and also the impact of increasing the duration of each hemodialysis session while reducing the frequency of hemodialysis and using larger surface area dialyzers, on the weekly hemodialysis dose.

\section{REFERENCES}

[1] Grace BS, Clayton P, Cass A, McDonald SP. Socio-economic status and incidence of renal replacement therapy: a registry study of Australian patients. Nephrology Dialysis Transplantation. 2012;27(11):4173-80.

[2] Hommel K, Rasmussen S, Kamper AL, Madsen M. Regional and social inequalities in chronic renal replacement therapy in Denmark. Nephrol Dial Transplant. 2010;25(8):2624-32.

[3] Morton RL, Schlackow I, Mihaylova B, Staplin ND, Gray A, Cass A. The impact of social disadvantage in moderate-to-severe chronic kidney disease: an equity-focused systematic review. Nephrol Dial Transplant. 2016;31(1):46-56.

[4] Misra M. The basics of hemodialysis equipment. Hemodial Int. 2005;9(1):30-6.

[5] Daugirdas JT, Blake PG, Ing TS. Handbook of Dialysis. Philadelphia: Wolters Kluwer Health; 2015.

[6] Leypoldt JK. Urea standard Kt/Vurea for assessing dialysis treatment adequacy. Hemod Int. 2004;8(2):193-7.

[7] Hakim R, Depner T, Parker T. Adequacy of hemodialysis. Am J Kid Dis. 1992;20(2):107-23. 
[8] Chowdhury N, Islam F, Zafreen F, Begum B, Sultana N, Perveen S, et al. Effect Of Surface Area Of Dialyzer Membrane On The Adequacy Of Haemodialysis. J Armed Forc Med Coll, Bangla. 2012;7(2):9-11.

[9] Panagoutsos S, Yannatos E, Passadakis P, Thodis E, Galtsidopoulos O, Vargemezis $\mathrm{V}$. The clinical impact of increasing the hemodialysis dose. Hemod Int 2001; 5: 51-4.

[10] Imtiaz S, Salman B, Qureshi R, Drohlia MF, Ahmad A. A review of the epidemiology of chronic kidney disease in Pakistan: A global and regional perspective. Saudi Journal of Kidney Diseases and Transplantation. 2018; 29(6): 1441 .

[11] Doig GS, Simpson F. Randomization and allocation concealment: a practical guide for researchers. J Crit Care. 2005; 20(2): 187-91; discussion 91-3.

[12] Galach M, Ciechanowska A, Sabalinska S, Waniewski J, Wojcicki J, Werynskis A. Impact of convective transport on dialyzer clearance. $J$ Artif Organs. 2003; 6(1): 42-8.

[13] Locatelli F, Manzoni C, Di Filippo S. The importance of convective transport. Kidney Int Suppl. 2002; 61(80): 115-20.

[14] Jaffrin MY. Convective mass transfer in hemodialysis. Artif Organs. 1995; 19(11): 1162-71.

[15] Jaffrin MY, Ding LH, Laurent JM. Simultaneous convective and diffusive mass transfers in a hemodialyser. J Biomech Eng. 1990; 112(2): 212-9.

[16] Sigdell JE. Calculation of combined diffusive and convective mass transfer. Int J Artif Organs. 1982; 5(6): 361-72.

[17] Gostoli C, Gatta A. Mass transfer in a hollow fiber dialyzer. $J$ Membrane Sci. 1980; 6: 133-48.

[18] Azar AT. Increasing dialysate flow rate increases dialyzer urea clearance and dialysis efficiency: an in vivo study. Saudi Journal of kidney diseases and transplantation. 2009; 20(6): 1023.

[19] Tokars JI, Alter MJ, Miller E, Moyer LA, Favero MS. National Surveillance of Dialysis Associated Diseases in the United States1994. ASAIO Journal. 1997; 43(1): 108-19.

[20] Kuchle C, Fricke H, Held E, Schiffl H. High-flux hemodialysis postpones clinical manifestation of dialysis-related amyloidosis. Am J Nephrol. 1996; 16(6): 484-8.

[21] McKane W, Chandna SM, Tattersall JE, Greenwood RN, Farrington $\mathrm{K}$. Identical decline of residual renal function in high-flux biocompatible hemodialysis and CAPD. Kidney Int. 2002; 61(1): 25665 .

[22] Goldberg IJ, Kaufman AM, Lavarias VA, Vanni-Reyes T, Levin NW High flux dialysis membranes improve plasma lipoprotein proffles in patients with end-stage renal disease. Nephrology Dialysis Transplantation. 1996; 11(supp2): 104-7.

[23] Robles NR, Murga L, Galvan S, Esparrago JF, Sanchez-Casado E. Hemodialysis with cuprophane or polysulfone: effects on uremic polyneuropathy. Am J Kidney Dis. 1993; 21(3): 282-7.

[24] Locatelli F, Mastrangelo F, Redaelli B, Ronco C, Marcelli D, La Greca $\mathrm{G}$, et al. Effects of different membranes and dialysis technologies on patient treatment tolerance and nutritional parameters. The Italian Cooperative Dialysis Study Group. Kidney Int. 1996; 50(4): 1293-302.

[25] House AA, Wells GA, Donnelly JG, Nadler SP, Hebert PC. Randomized trial of high-flux vs low-flux haemodialysis: effects on homocysteine and lipids. Nephrol Dial Transplant. 2000; 15(7): 102934.

[26] Hoen B, Paul-Dauphin A, Hestin D, Kessler MJJotASoN EPIBACDIAL: a multicenter prospective study of risk factors for bacteremia in chronic hemodialysis patients. Journal of the American Society of Nephrology. 1998; 9(5): 869-76. 